\title{
Effects of oregano, carvacrol and thymol on Staphylococcus aureus and Staphylococcus epidermidis biofilms
}

Correspondence

Antonia Nostro

atnostro@pharma.unime.it

Received 27 June 2006

Accepted 18 December 2006

\author{
Antonia Nostro, ${ }^{1}$ Andrea Sudano Roccaro, ${ }^{2}$ Giuseppe Bisignano, ${ }^{1}$ \\ Andreana Marino, ${ }^{1}$ Maria A. Cannatelli, ${ }^{1}$ Francesco C. Pizzimenti, ${ }^{1}$ \\ Pier Luigi Cioni, ${ }^{3}$ Francesca Procopio ${ }^{1}$ and Anna Rita Blanco ${ }^{2}$ \\ ${ }^{1}$ Dipartimento Farmaco-Biologico, Facoltà di Farmacia, Università degli Studi di Messina, Villaggio \\ Annunziata, 98168 Messina, Italy \\ ${ }^{2}$ Direzione Ricerca, Sviluppo \& Innovazione, SIFI SpA, Via Ercole Patti 36, Lavinaio, 95020 Catania, \\ Italy \\ ${ }^{3}$ Dipartimento di Chimica Bioorganica e Biofarmacia, Università di Pisa, Via Bonanno 33, 56126 \\ Pisa, Italy
}

\section{INTRODUCTION}

Staphylococci are important nosocomial pathogens. Eradication of these micro-organisms is not always successful due to their ability to form biofilms. Experimental evidence has shown that micro-organisms in biofilms are less susceptible to conventional treatment (Brown \& Gilbert, 1993) than their planktonic counterparts. Many factors contribute to the lowered susceptibility of bacteria enclosed in a biofilm, and include the induction of a biofilm phenotype, the stress response and failure of the antimicrobial agents to penetrate the biofilm (Mah \& O'Toole, 2001).

As such, alternative strategies or more effective agents exhibiting activity against biofilm-producing micro-organisms are of great interest. Natural drugs could represent an interesting approach to limit the emergence and the spread of these organisms, which currently are difficult to treat. Recently, there has been considerable interest in the study of plant materials as sources of new compounds for processing into therapeutic agents. One approach may be the use of essential oils that have been shown to be potential agents in the treatment of infections, and are safe in terms of human and animal health. In this context, oregano oil and

Abbreviations: BEC, biofilm eradication concentration; BIC, biofilm inhibitory concentration; MBC, minimum bactericidal concentration. its major phenolic components, carvacrol [2-methyl5-(1-methylethyl)phenol] and thymol (2-isopropyl-5methylphenol), are known for their wide spectrum of antimicrobial activity, which has been the subject of several investigations in vitro (Dorman \& Deans, 2000; Lambert et al., 2001) and in vivo (Adam et al., 1998; Manohar et al., 2001). They possess multiple biological properties such as anti-inflammatory, anti-leishmanial, antioxidant, hepatoprotective and anti-tumoral activities (Aeschbach et al., 1994; Alam et al., 1999; Robledo et al., 2005; Skold et al., 1998; Weber \& de Bont, 1996; Zeytinoglu et al., 2003).

Previously, we have shown the efficacy of oregano oil, carvacrol and thymol against planktonic Staphylococcus aureus and Staphylococcus epidermidis, including meticillinresistant strains (Nostro et al., 2004). The objective of this study was to extend the research to evaluate the activity of oregano oil, carvacrol and thymol on biofilm-grown $S$. aureus and S. epidermidis strains, as well as the effects of oils on biofilm formation.

\section{METHODS}

Essential oils. The aerial parts of commercial Origanum vulgare L. (obtained from A. Minardi, Ravenna, Italy) were subjected to hydrodistillation. The qualitative and quantitative composition of the essential oil was analysed by GC and GC/electron impact MS as 
described previously (Nostro et al., 2004). The oregano oil was characterized principally by carvacrol and thymol (14 and $24.7 \%$, v/v, respectively) and by their two precursors, $\gamma$-terpinene and $p$-cymene (11.7 and $14.6 \%, \mathrm{v} / \mathrm{v}$, respectively). Carvacrol ( $\geqslant 97.0 \%$ pure) and thymol $(\geqslant 99.0 \%$ pure $)$ were purchased from Aldrich. Stock solutions of $50 \%(\mathrm{v} / \mathrm{v})$ essential oils were prepared in ethanol $(\mathrm{EtOH})$ and used following dilution.

Bacterial strains. The bacteria used were $S$. aureus $(n=6)$ and $S$. epidermidis $(n=5)$ isolated from ocular infections belonging to our private collection, and the reference strain S. epidermidis ATCC 35984 (slime producing). Each isolate was characterized for biofilm-related properties as reported previously (Blanco et al., 2005). The isolates were capable of forming biofilms with an $\mathrm{OD}_{492}$ ranging from 0.52 to 1.55 (Blanco et al., 2005).

Efficacy of oregano oil on planktonic cells. The MIC and minimum bactericidal concentration (MBC) of oregano, carvacrol and thymol on planktonic cells were determined in tryptic soy broth (TSB) using a broth dilution micromethod in polystyrene flat-bottomed microtitre plates (Costar Corning) according to CLSI guidelines (Clinical Laboratory Standards Institute, 2000). The data from at least five replicates were evaluated and modal results were calculated. Two growth controls consisting of TSB medium and TSB $\mathrm{EtOH}_{\mathrm{E}}$ were included

Effect on established biofilms. The effect on established biofilms was verified as described by Johnson et al. (2002) with some modifications. All isolates were grown as biofilms using polystyrene flatbottomed microtitre plates. After $24 \mathrm{~h}$ of incubation at $37{ }^{\circ} \mathrm{C}$, the planktonic-phase cells were gently removed and the wells were washed three times with PBS and filled with $200 \mu$ twofold dilutions of the oils, ranging from the MIC to a 16-fold dilution of the MIC. The plates were incubated for $24 \mathrm{~h}$ at $37{ }^{\circ} \mathrm{C}$. The $\mathrm{OD}_{492}$ was measured at time 0 and after incubation for $24 \mathrm{~h}$. The biofilm inhibitory concentration (BIC) was determined as the lowest concentration where no growth occurred in the supernatant fluid, confirmed by no increase in optical density compared with the initial reading. Samples of biofilms from the bottom of these wells were scarified by a metal loop, spread over the surface of tryptic soy agar (TSA) plates and incubated for $72 \mathrm{~h}$ at $37^{\circ} \mathrm{C}$. The biofilm eradication concentration (BEC) was determined as the lowest concentration at which no bacterial growth occurred on the TSA plates. Data from at least five replicates were evaluated and modal results were calculated. Two biofilm controls consisting of TSB medium and $\mathrm{TSB}_{\mathrm{EtOH}}$ were included.

Effect on biofilm formation. The effect of different concentrations of oil (ranging from 0.5 to $0.125 \mathrm{MIC}$ ) on biofilm-forming ability was tested on polystyrene flat-bottomed microtitre plates as described by Cramton et al. (1999) with some modifications. Cultures were grown overnight in $10 \mathrm{ml}$ TSB with $1 \%$ glucose, diluted in growth medium to $5 \times 10^{5}$ c.f.u. $\mathrm{ml}^{-1}$ and $100 \mu \mathrm{l}$ was dispensed into each well of 96well polystyrene flat-bottomed microtitre plates in the presence of $100 \mu$ l subinhibitory concentrations (subMIC) of oregano, carvacrol and thymol (0.5, 0.25 and $0.125 \mathrm{MIC}$ ) or $100 \mu \mathrm{l}$ medium (control). After incubation for $24 \mathrm{~h}$ at $37^{\circ} \mathrm{C}$, each well was washed twice with sterile PBS (pH 7.4), dried, stained for 1 min with $0.1 \%$ safranin and washed with water. The stained biofilms were resuspended in $200 \mu \mathrm{l}$ $\mathrm{PBS}$ and $\mathrm{OD}_{492}$ was measured by spectrophotometry using an ELISA reader. Two biofilm controls consisting of TSB medium and TSB $\mathrm{EtOH}_{\mathrm{H}}$ were included. Each assay was performed in quadruplicate and repeated at least three times. As a measure of efficacy, relative biofilm formation was defined as follows: (mean $\mathrm{OD}_{492}$ of treated well/mean $\mathrm{OD}_{492}$ of control well) $\times 100$.

Scanning electron microscopy. Biofilms of a strong biofilm producer (S. aureus 815 ) formed on polystyrene flat-bottomed microtitre plates in the presence or absence of subMIC concentrations of carvacrol ( 0.5 and $0.25 \mathrm{MIC}$ ) were fixed in $2 \%$ glutaraldehyde in $0.1 \mathrm{M}$ PBS for $2 \mathrm{~h}$ at $4{ }^{\circ} \mathrm{C}$ and then post-fixed for $1 \mathrm{~h}$ at $4{ }^{\circ} \mathrm{C}$ in $1 \%$ osmium tetroxide in the same buffer. After thorough washing with PBS, samples were dehydrated in a series of ethanol solutions (30-100 \%). Specimens were mounted on aluminium stubs with conductive carbon cement, allowed to dry and then coated with a gold film. Samples were observed with an S-400 scanning electron microscope (Hitachi).

Statistical analysis. The biofilm formation values were analysed by a hierarchical analysis of variance test following angular transformation. The differences between groups (different oil concentrations) were considered significant when $P<0.05$. Where significant differences existed, the Duncan test was performed to verify the significant difference levels.

\section{RESULTS AND DISCUSSION}

In this study, the in vitro effects of $O$. vulgare essential oil, carvacrol and thymol on staphylococcal biofilms were evaluated. Remarkably, the in vitro activity of the oils on biofilm was only slightly lower than that on planktonic culture (Table 1). For most of the strains tested, the BIC $(0.125-0.500 \%, \mathrm{v} / \mathrm{v}$, for oregano, and $0.031-0.125 \%, \mathrm{v} / \mathrm{v}$, for carvacrol and thymol) and BEC (0.25-1.0\%, v/v, for oregano, and $0.125-0.500 \%, \mathrm{v} / \mathrm{v}$, for carvacrol and thymol) values were twofold or fourfold greater than the concentration required to inhibit growth in suspension.

Despite a different inhibitory effect among the strains, a general attenuated level of biofilm formation in the presence of subinhibitory concentrations of oregano, carvacrol and thymol was observed (Table 2). Significant differences $(P<0.05)$ in biofilm formation values were observed between groups (different oil concentrations). Doses of 0.5 MIC produced a greater influence than doses of 0.25 and 0.125 MIC (Duncan test). This effect was more evident for $S$. aureus than for S. epidermidis strains. In the presence of oregano, carvacrol and thymol (0.5 MIC), the mean biofilm formation values were equal to $46.7,28.3$ and $30.1 \%$ for S. aureus, and 58.9, 57.1 and $54.4 \%$ for $S$. epidermidis, respectively. Oregano showed a slight inhibitory effect because carvacrol and thymol represent only a fraction $(38.7 \%)$ of the entire essence and they interact in an additive rather than a synergistic way (Lambert et al., 2001).

Direct observation by scanning electron microscopy of $S$. aureus 815 showed that, after $24 \mathrm{~h}$, in the absence of carvacrol (Fig. 1a, b), bacterial cells formed evident biofilms with matrix material. In the presence of carvacrol at concentrations of 0.5 and 0.25 MIC (Fig. 1c, d, e), bacterial cells grew as looser colonies, and the amount of biofilm was reduced, being almost absent at 0.5 MIC.

Having more-effective antimicrobial agents that are also active against biofilm, and are able to prevent or at least interfere with biofilm formation, would be a considerable achievement. As an extension of our earlier work on the efficacy of oregano, carvacrol and thymol against planktonic meticillin-resistant staphylococci (Nostro et al., 
Table 1. Susceptibility of planktonic and biofilm organisms to oregano (O), carvacrol (C) and thymol (T)

\begin{tabular}{|c|c|c|c|c|c|}
\hline Strain & Agent & $\begin{array}{c}\text { MIC } \\
(\%, \mathrm{v} / \mathrm{v})\end{array}$ & $\begin{array}{c}\text { BIC } \\
(\%, \mathrm{v} / \mathrm{v})\end{array}$ & $\begin{array}{c}\text { MBC } \\
(\%, \mathrm{v} / \mathrm{v})\end{array}$ & $\begin{array}{c}\text { BEC } \\
(\%, \mathrm{v} / \mathrm{v})\end{array}$ \\
\hline \multicolumn{6}{|l|}{ S. aureus } \\
\hline \multirow{3}{*}{$6 \mathrm{ME}$} & $\mathrm{O}$ & 0.062 & 0.250 & 0.125 & 0.500 \\
\hline & C & 0.015 & 0.062 & 0.062 & 0.250 \\
\hline & $\mathrm{T}$ & 0.031 & 0.062 & 0.062 & 0.250 \\
\hline \multirow[t]{3}{*}{$810 \mathrm{CT}$} & $\mathrm{O}$ & 0.125 & 0.500 & 0.250 & 0.500 \\
\hline & $\mathrm{C}$ & 0.031 & 0.125 & 0.062 & 0.250 \\
\hline & $\mathrm{T}$ & 0.031 & 0.062 & 0.062 & 0.125 \\
\hline \multirow[t]{3}{*}{$815 \mathrm{CT}$} & $\mathrm{O}$ & 0.062 & 0.250 & 0.125 & 0.500 \\
\hline & $\mathrm{C}$ & 0.031 & 0.125 & 0.125 & 0.500 \\
\hline & $\mathrm{T}$ & 0.031 & 0.062 & 0.062 & 0.125 \\
\hline \multirow[t]{3}{*}{$808 \mathrm{CT}$} & $\mathrm{O}$ & 0.125 & 0.250 & 0.125 & 1 \\
\hline & $\mathrm{C}$ & 0.031 & 0.125 & 0.062 & 0.250 \\
\hline & $\mathrm{T}$ & 0.031 & 0.062 & 0.062 & 0.125 \\
\hline \multirow[t]{3}{*}{$5 \mathrm{ME}$} & $\mathrm{O}$ & 0.062 & 0.250 & 0.125 & 0.500 \\
\hline & $\mathrm{C}$ & 0.031 & 0.062 & 0.125 & 0.250 \\
\hline & $\mathrm{T}$ & 0.031 & 0.125 & 0.062 & 0.250 \\
\hline \multirow[t]{3}{*}{$74 \mathrm{CCH}$} & $\mathrm{O}$ & 0.062 & 0.250 & 0.125 & 0.500 \\
\hline & $\mathrm{C}$ & 0.015 & 0.031 & 0.062 & 0.125 \\
\hline & $\mathrm{T}$ & 0.062 & 0.125 & 0.125 & 0.250 \\
\hline \multicolumn{6}{|c|}{ S. epidermidis } \\
\hline \multirow[t]{3}{*}{ ATCC 35984} & $\mathrm{O}$ & 0.125 & 0.500 & 0.250 & 1 \\
\hline & $\mathrm{C}$ & 0.031 & 0.125 & 0.125 & 0.500 \\
\hline & $\mathrm{T}$ & 0.062 & 0.125 & 0.125 & 0.500 \\
\hline \multirow[t]{3}{*}{$14 \mathrm{ME}$} & $\mathrm{O}$ & 0.062 & 0.125 & 0.125 & 0.500 \\
\hline & $\mathrm{C}$ & 0.031 & 0.125 & 0.125 & 0.500 \\
\hline & $\mathrm{T}$ & 0.031 & 0.062 & 0.062 & 0.125 \\
\hline \multirow[t]{3}{*}{$807 \mathrm{CT}$} & $\mathrm{O}$ & 0.125 & 0.500 & 0.250 & 1 \\
\hline & $\mathrm{C}$ & 0.031 & 0.062 & 0.062 & 0.125 \\
\hline & $\mathrm{T}$ & 0.031 & 0.125 & 0.062 & 0.125 \\
\hline \multirow[t]{3}{*}{813} & $\mathrm{O}$ & 0.125 & 0.250 & 0.250 & 0.500 \\
\hline & $\mathrm{C}$ & 0.031 & 0.125 & 0.062 & 0.125 \\
\hline & $\mathrm{T}$ & 0.031 & 0.062 & 0.062 & 0.125 \\
\hline \multirow[t]{3}{*}{$23 \mathrm{~S}$} & $\mathrm{O}$ & 0.125 & 0.250 & 0.250 & 0.250 \\
\hline & $\mathrm{C}$ & 0.015 & 0.031 & 0.031 & 0.125 \\
\hline & $\mathrm{T}$ & 0.031 & 0.031 & 0.062 & 0.125 \\
\hline \multirow[t]{3}{*}{809} & $\mathrm{O}$ & 0.125 & 0.250 & 0.250 & 0.500 \\
\hline & $\mathrm{C}$ & 0.015 & 0.031 & 0.062 & 0.250 \\
\hline & $\mathrm{T}$ & 0.031 & 0.062 & 0.062 & 0.125 \\
\hline
\end{tabular}

2004), we show here that these oils inhibited growth of preformed biofilm and interfered with biofilm formation during planktonic growth. The reasons for this could be due to many factors acting either synergistically or alone. The antimicrobial activity of oregano oil is mostly attributed to the action of its principal phenolic components, carvacrol and thymol, which exhibit significant bactericidal activity when tested separately (Friedman et al., 2002; Juven et al., 1994; Lambert et al., 2001; Ultee et al., 1998). Due to their hydrophobic nature, carvacrol and thymol interact with the lipid bilayer of cytoplasmic membranes causing loss of integrity and leakage of cellular material such as ions, ATP and nucleic acid (Helander et al., 1998; Lambert et al. 2001; Trombetta et al., 2005; Ultee et al.,
Table 2. Effects of oregano (O), carvacrol (C) and thymol (T) on biofilm formation

\begin{tabular}{|c|c|c|c|c|}
\hline \multirow[t]{2}{*}{ Strain } & \multirow[t]{2}{*}{ Agent } & \multicolumn{3}{|c|}{ Biofilm formation ${ }^{\star}$} \\
\hline & & $0.5 \mathrm{MIC}$ & $0.25 \mathrm{MIC}$ & 0.125 MIC \\
\hline \multicolumn{5}{|l|}{ S. aureus } \\
\hline \multirow[t]{3}{*}{$6 \mathrm{ME}$} & $\mathrm{O}$ & $52.45 \pm 6.3$ & $73.3 \pm 8.2$ & $103 \pm 10$ \\
\hline & $\mathrm{C}$ & $34.8 \pm 5.1$ & $90.8 \pm 9.5$ & $96.8 \pm 9.8$ \\
\hline & $\mathrm{T}$ & $49.9 \pm 3$ & $98.4 \pm 9.6$ & $96.9 \pm 7.2$ \\
\hline \multirow[t]{3}{*}{$810 \mathrm{CT}$} & $\mathrm{O}$ & $50.3 \pm 6.1$ & $63.4 \pm 7.3$ & $93.9 \pm 9$ \\
\hline & $\mathrm{C}$ & $41.2 \pm 5.6$ & $75.6 \pm 8.4$ & $76.5 \pm 8.4$ \\
\hline & $\mathrm{T}$ & $20.9 \pm 1.2$ & $72.6 \pm 8$ & $76.8 \pm 8.4$ \\
\hline \multirow[t]{3}{*}{$815 \mathrm{CT}$} & $\mathrm{O}$ & $10.6 \pm 1.4$ & $17.1 \pm 4.1$ & $79.33 \pm 8.6$ \\
\hline & $\mathrm{C}$ & $3.1 \pm 4.2$ & $19.9 \pm 5$ & $62 \pm 3.2$ \\
\hline & $\mathrm{T}$ & $3.48 \pm 3.2$ & $20 \pm 2$ & $71.3 \pm 8.4$ \\
\hline \multirow[t]{3}{*}{$808 \mathrm{CT}$} & $\mathrm{O}$ & $6.23 \pm 5.2$ & $30.7 \pm 3.6$ & $95.9 \pm 9.7$ \\
\hline & $\mathrm{C}$ & $8.3 \pm 2.5$ & $25.9 \pm 2.7$ & $35 \pm 7.4$ \\
\hline & $\mathrm{T}$ & $14.9 \pm 1.5$ & $20 \pm 2$ & $48 \pm 5.9$ \\
\hline \multirow[t]{3}{*}{$5 \mathrm{ME}$} & $\mathrm{O}$ & $50 \pm 1.2$ & $78.1 \pm 2.3$ & $95 \pm 6$ \\
\hline & $\mathrm{C}$ & $40.1 \pm 3$ & $75.2 \pm 4$ & $98.4 \pm 10.1$ \\
\hline & $\mathrm{T}$ & $49.1 \pm 2.3$ & $72 \pm 1.3$ & $96.9 \pm 2.3$ \\
\hline \multirow[t]{3}{*}{$74 \mathrm{CCH}$} & $\mathrm{O}$ & $24.4 \pm 2.3$ & $53.4 \pm 6.4$ & $83 \pm 8.8$ \\
\hline & $\mathrm{C}$ & $32.3 \pm 4.6$ & $66.4 \pm 7.8$ & $101 \pm 8.2$ \\
\hline & $\mathrm{T}$ & $23.2 \pm 2$ & $73.27 \pm 8.1$ & $118 \pm 11.2$ \\
\hline \multicolumn{5}{|l|}{ S. epidermidis } \\
\hline \multirow[t]{3}{*}{ ATCC 35984} & $\mathrm{O}$ & $65 \pm 4.9$ & $72.4 \pm 8$ & $98.8 \pm 9.6$ \\
\hline & $\mathrm{C}$ & $70.9 \pm 8.2$ & $99 \pm 9.9$ & $98.16 \pm 9.9$ \\
\hline & $\mathrm{T}$ & $71.67 \pm 8$ & $102 \pm 10$ & $102 \pm 10.1$ \\
\hline \multirow[t]{3}{*}{$14 \mathrm{ME}$} & $\mathrm{O}$ & $33.46 \pm 2$ & $81.9 \pm 8.5$ & $95.88 \pm 7.6$ \\
\hline & $\mathrm{C}$ & $40 \pm 3.2$ & $64.6 \pm 6.8$ & $104 \pm 10.3$ \\
\hline & $\mathrm{T}$ & $31.24 \pm 4$ & $36 \pm 2$ & $71.5 \pm 7.5$ \\
\hline \multirow[t]{3}{*}{807 CT } & $\mathrm{O}$ & $58 \pm 6.9$ & $85.6 \pm 9$ & $103 \pm 10$ \\
\hline & $\mathrm{C}$ & $22.9 \pm 1.9$ & $41.6 \pm 5.2$ & $81.7 \pm 8.78$ \\
\hline & $\mathrm{T}$ & $22.56 \pm 1.8$ & $28.5 \pm 3$ & $64.1 \pm 7.4$ \\
\hline \multirow[t]{3}{*}{813 CT } & $\mathrm{O}$ & $25.5 \pm 2.6$ & $72.4 \pm 8.1$ & $111 \pm 10.6$ \\
\hline & $\mathrm{C}$ & $48 \pm 3$ & $79.2 \pm 8.6$ & $87.5 \pm 9.2$ \\
\hline & $\mathrm{T}$ & $40.1 \pm 1.3$ & $75.8 \pm 8.3$ & $98.1 \pm 9.8$ \\
\hline \multirow[t]{3}{*}{$23 \mathrm{~S}$} & $\mathrm{O}$ & $81.8 \pm 8$ & $107.3 \pm 10$ & $101 \pm 10$ \\
\hline & $\mathrm{C}$ & $47.2 \pm 5.8$ & $93.9 \pm 9.6$ & $106 \pm 10.4$ \\
\hline & $\mathrm{T}$ & $25.2 \pm 2.5$ & $60.5 \pm 7$ & $76.8 \pm 8.4$ \\
\hline \multirow[t]{3}{*}{809} & $\mathrm{O}$ & $70 \pm 7.9$ & $94.4 \pm 9.6$ & $97.3 \pm 9.8$ \\
\hline & $\mathrm{C}$ & $43.4 \pm 5.4$ & $65.3 \pm 7.5$ & $86 \pm 4.1$ \\
\hline & $\mathrm{T}$ & $24 \pm 2.2$ & $73.9 \pm 8.2$ & $82.6 \pm 8.8$ \\
\hline
\end{tabular}

${ }^{*}$ Biofilm formation values were calculated as: $\left(\right.$ mean $\mathrm{OD}_{492}$ treated well $) /\left(\right.$ mean $\mathrm{OD}_{492}$ control well $) \times 100$. Values are expressed as means $\pm \mathrm{SD}$.

1999). The extent of membrane damage induced by a compound can be related to its intrinsic hydrophobicity, which can be determined experimentally by its partition coefficient in octanol/water $\left(P_{\mathrm{o} / \mathrm{w}}\right)$. Carvacrol and thymol have a $\log P_{\mathrm{o} / \mathrm{w}}$ of 3.64 and 3.30, respectively (Griffin et al., 1999; Ultee et al., 2002). Weber \& de Bont (1996) reported that compounds with a $\log P_{\mathrm{o} / \mathrm{w}}$ value higher than 3 will partition deeply in the cell membrane. However, carvacrol and thymol have been reported to possess a relative 

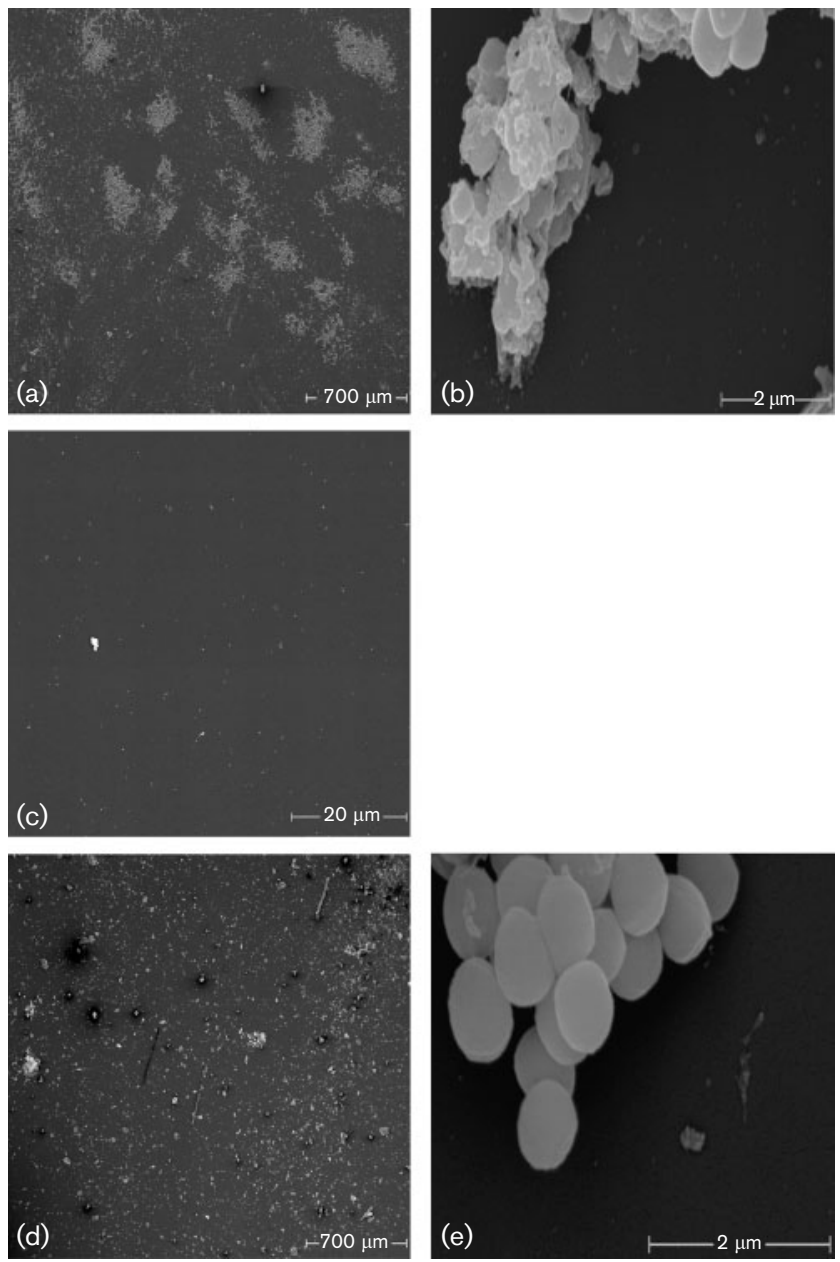

Fig. 1. Scanning electron micrographs of $S$. aureus 815 biofilms formed on polystyrene flat-bottomed microtitre plates: $(a, b)$ biofilm control, (c) biofilm formed in the presence of $0.5 \mathrm{MIC}$ of carvacrol, $(\mathrm{d}, \mathrm{e})$ biofilm formed in the presence of $0.25 \mathrm{MIC}$ of carvacrol.

hydrophilicity, having a water solubility of $830 \pm 10$ and $846 \pm 9$ p.p.m., respectively (Griffin et al., 1999). Hence, carvacrol and thymol, alone or in oregano oil, could diffuse through the polysaccharide matrix of the biofilm and destabilize it due to their strong intrinsic antimicrobial properties. This hypothesis is supported by the anti-plaque effects of a thymol-based mouthwash, in part attributable to rapid-kill and plaque-permeating abilities (Ouhayoun, 2003).

Carvacrol and thymol may also be responsible for the effects observed on biofilm formation. Knowles et al. (2005) suggested that continued exposure of S. aureus to non-biocidal concentrations of carvacrol disrupted normal development of dual-species biofilm, preventing the build up of protein mass, arresting at the microcolony stage. Alternatively, the oils could interact with surface proteins, leading to an alteration of the bacterial cell surface and in part compromising the initial attachment phase to polystyrene microtitre plates. In this context, Juven et al. (1994) suggested a reaction between phenolic compounds (such as thymol) and bacterial membrane proteins.

The findings of the present study highlight the promising role of oregano, carvacrol and thymol as new lead structures in the search for novel antibacterial agents. Data in the literature on the availability and pharmacokinetics of carvacrol and thymol (Bhattaram et al., 2002; De Vincenzi et al., 2004), and on acute and short-term in vivo effects, suggest that they may not pose a risk for human and animal health (Chami et al., 2005; Stammati et al., 1999). Therefore, further experiment may be worthy of evaluation.

\section{ACKNOWLEDGEMENTS}

We thank Pino Mondio of the Biomedical Science Department, Section of General and Cellular Biology and Molecular Genetics of the University of Catania, Italy, for expert collaboration in the realization of the scanning electron microscopy artwork.

\section{REFERENCES}

Adam, K., Sivropoulou, A., Kokkini, S., Lanaras, T. \& Arsenakis, M. (1998). Antifungal activity of Origanum vulgare subsp. hirtum, Mentha spicata, Lavandula angustifolia, and Salvia fruticosa essential oils against human pathogenic fungi. J Agric Food Chem 46, 1739-1745.

Aeschbach, R., Loliger, J., Scott, B. C., Murcia, A., Butler, J., Halliwell, B. \& Aruoma, O. I. (1994). Antioxidant actions of thymol, carvacrol, 6-gingerol, zingerone and hydroxytyrosol. Food Chem Toxicol 32, 31-36.

Alam, K., Nagi, M. N., Badary, O. A., Al-Shabanah, O. A., Al-Rikabi, A. C. \& Al-Bekairi, A. M. (1999). The protective action of thymol against carbon tetrachloride hepatotoxicity in mice. Pharmacol Res 40 , 159-163.

Bhattaram, V. A., Graefe, U., Kohlert, C., Veit, M. \& Derendorf, H. (2002). Pharmacokinetics and bioavailability of herbal medicinal products. Phytomedicine 9 (Suppl. 3), 1-33.

Blanco, A. R., Sudano-Roccaro, A., Spoto, G. C., Nostro, A. \& Rusciano, D. (2005). Epigallocatechin gallate inhibits biofilm formation by ocular staphylococcal isolates. Antimicrob Agents Chemother 49, 4339-4343.

Brown, M. R. W. \& Gilbert, P. (1993). Sensitivity of biofilms to antimicrobial agents. J Appl Bacteriol 74, 87S-97S.

Chami, N., Bennis, S., Chami, F., Aboussekhra, A. \& Remmal, A. (2005). Study of anticandidal activity of carvacrol and eugenol in vitro and in vivo. Oral Microbiol Immunol 20, 106-111.

Clinical Laboratory Standards Institute (2000). Methods for Dilution Antimicrobial Susceptibility Tests for Bacteria that Grow Aerobically, approved standard M7-A5. Wayne, PA: Clinical Laboratory Standards Institute.

Cramton, S. E., Gerke, C., Schnell, N. F., Nichols, W. W. \& Götz, F. (1999). The intercellular adhesion (ica) locus in Staphylococcus aureus and is required for biofilm formation. Infect Immun 67, 5427-5433.

De Vincenzi, M., Stammati, A., De Vincenzi, A. \& Silano, M. (2004). Constituents of aromatic plants: carvacrol. Fitoterapia 75, 801-804.

Dorman, H. J. D. \& Deans, S. G. (2000). Antimicrobial agents from plants: antibacterial activity of plant volatile oils. J Appl Microbiol 88, 308-316.

Friedman, M., Henika, P. R. \& Mandrell, R. E. (2002). Bactericidal activities of plant essential oils and some of their isolated constituents 
against Campylobacter jejuni, Escherichia coli, Listeria monocytogenes, and Salmonella enterica. J Food Prot 65, 1545-1560.

Griffin, S. G., Wyllie, S. G., Markham, J. L. \& Leach, D. (1999). The role of structure and molecular properties of terpenoids in determining their antimicrobial activity. Flavour Fragr J 14, 322-332.

Helander, I. M., Alakomi, H. L., Latva-Kala, K., Mattila-Sandholm, T., Pol, I., Smid, E. J., Gorris, L. G. M. \& von Wright, A. (1998). Characterization of the action of selected essential oil components on Gram-negative bacteria. J Agric Food Chem 46, 3590-3595.

Johnson, S. A., Goddard, P. A., Iliffe, C., Timmins, B., Rickard, A. H., Robson, G. \& Handley, P. S. (2002). Comparative susceptibility of resident and transient hand bacteria to para-chloro-meta-xylenol and triclosan. J Appl Microbiol 93, 336-344.

Juven, B. J., Kanner, J., Schved, F. \& Weisslowicz, H. (1994). Factors that interact with the antibacterial action of thyme essential oil and its active constituents. J Appl Bacteriol 76, 626-631.

Knowles, J. R., Roller, S., Murray, D. B. \& Naidu, A. S. (2005). Antimicrobial action of carvacrol at different stages of dual-species biofilm development by Staphylococcus aureus and Salmonella enterica serovar Typhimurium. Appl Environ Microbiol 71, 797-803.

Lambert, R. J. W., Skandamis, P. N., Coote, P. J. \& Nychas, G. J. E. (2001). A study of the minimum inhibitory concentration and mode of action of oregano essential oil, thymol and carvacrol. J Appl Microbiol 91, 453-462.

Mah, T.-F. C. \& O'Toole, G. A. (2001). Mechanisms of biofilm resistance to antimicrobial agents. Trends Microbiol 9, 34-39.

Manohar, V., Ingram, C., Gray, J., Talpur, N. A., Echard, B. W., Bagchi, D. \& Preuss, G. (2001). Antifungal activities of origanum oil against Candida albicans. Mol Cell Biochem 228, 111-117.

Nostro, A., Blanco, A. R., Cannatelli, M. A., Enea, V., Flamini, G., Morelli, I., Sudano Roccaro, A. \& Alonzo, V. (2004). Susceptibility of methicillin-resistant staphylococci to oregano essential oil, carvacrol and thymol. FEMS Microbiol Lett 230, 191-195.
Ouhayoun, J. P. (2003). Penetrating the plaque biofilm: impact of essential oil mouthwash. J Clin Periodontol 30 (Suppl. 5), 10-12.

Robledo, S., Osorio, E., Munoz, D., Jaramillo, L. M., Restrepo, A., Arango, G. \& Velez, I. (2005). In vitro and in vivo cytotoxicities and antileishmanial activities of thymol and hemisynthetic derivatives. Antimicrob Agents Chemother 49, 1652-1655.

Skold, K., Twetman, S., Hallgren, A., Yucel-Lindberg, T. \& Modeer, T. (1998). Effect of a chlorhexidine/thymol-containing varnish on prostaglandin E2 levels in gingival crevicular fluid. Eur J Oral Sci 106, 571-575.

Stammati, A., Bonsi, P., Zucco, F., Moezelaar, R., Alakomi, H. L. \& von Wright, A. (1999). Toxicity of selected plant volatiles in microbial and mammalian short-term assays. Food Chem Toxicol 37, 813-823.

Trombetta, D., Castelli, F., Sarpietro, M. G., Venuti, V., Cristani, M., Daniele, C., Saija, A., Mozzanti, G. \& Bisignano, G. (2005). Mechanisms of antibacterial action of three monoterpenes. Antimicrob Agents Chemother 49, 2474-2478.

Ultee, A., Gorris, L. G. \& Smid, E. J. (1998). Bactericidal activity of carvacrol towards the food-borne pathogen Bacillus cereus. J Appl Microbiol 85, 211-218.

Ultee, A., Kets, E. P. W. \& Smid, J. (1999). Mechanisms of action of carvacrol on the food-borne pathogen Bacillus cereus. Appl Environ Microbiol 65, 4606-4610.

Ultee, A., Bennik, M. H. \& Moezelaar, R. (2002). The phenolic hydroxyl group of carvacrol is essential for action against the food-borne pathogen Bacillus cereus. Appl Environ Microbiol 68, 1561-1568.

Weber, F. J. \& de Bont, J. A. (1996). Adaptation mechanisms of microorganisms to the toxic effects of organic solvents on membranes. Biochim Biophys Acta 1286, 225-245.

Zeytinoglu, H., Incesu, Z. \& Baser, K. H. (2003). Inhibition of DNA synthesis by carvacrol in mouse myoblast cells bearing a human $\mathrm{N}$ RAS oncogene. Phytomedicine 10, 292-299. 